Supplement of Biogeosciences Discuss., 12, 8573-8614, 2015

http://www.biogeosciences-discuss.net/12/8573/2015/

doi:10.5194/bgd-12-8573-2015-supplement

(C) Author(s) 2015. CC Attribution 3.0 License.

(c) (i)

Supplement of

\title{
Integrated radar and lidar analysis reveals extensive loss of remaining intact forest on Sumatra 2007-2010
}

M. B.Collins and E. T. A. Mitchard

Correspondence to: M. B. Collins (murray.collins@ed.ac.uk)

The copyright of individual parts of the supplement might differ from the CC-BY 3.0 licence. 


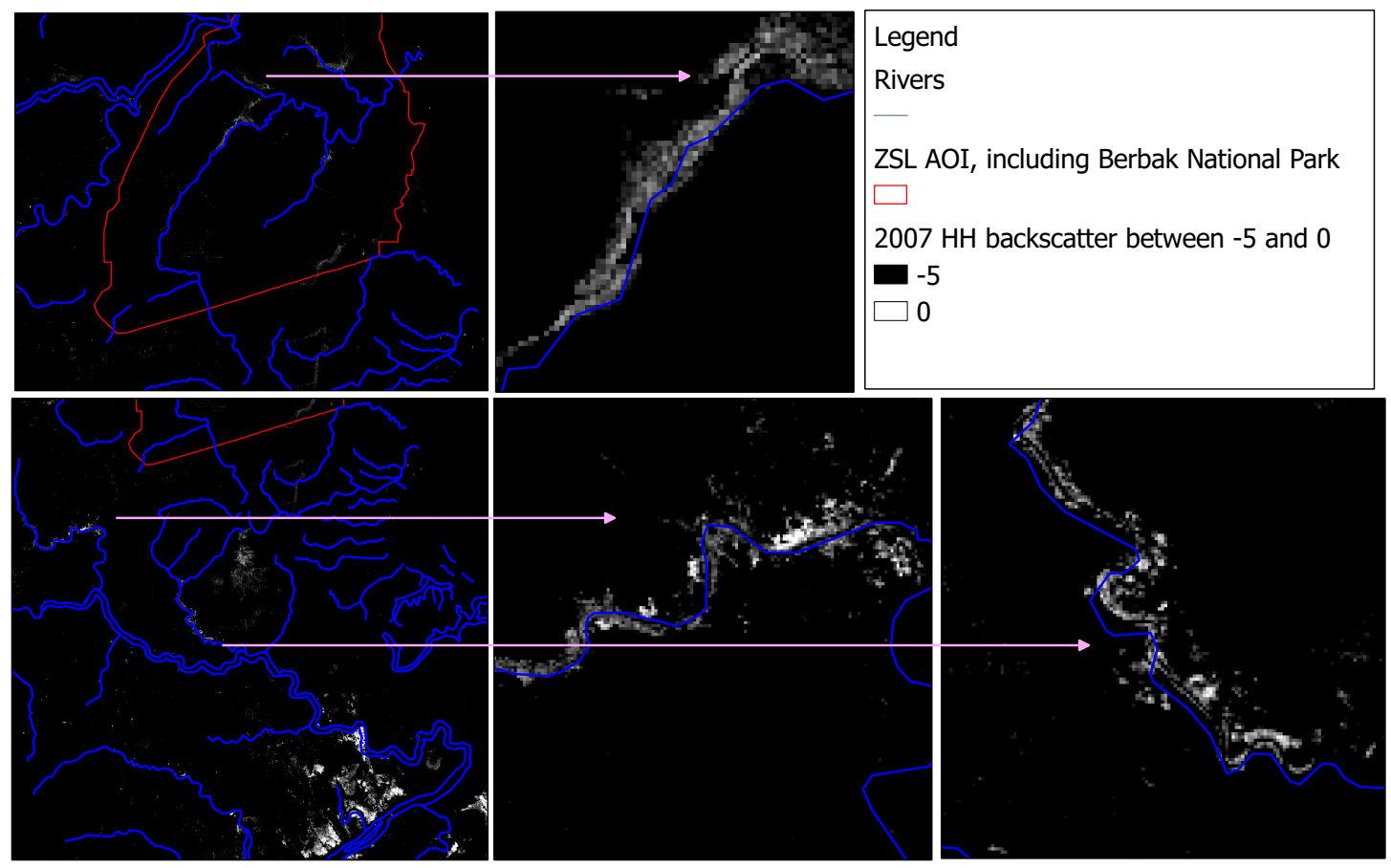

Figure 1: SI 1. This map shows the a shapefile of the rivers of Sumatra overlaid on the $2007 \mathrm{HH}$ backscatter data, which is restricted to show only those values between -5 and 0 . Areas $<-5$ are shown as black. The figures zoom in on areas next to rivers with high $\mathrm{HH}$ values $(>-5)$ 